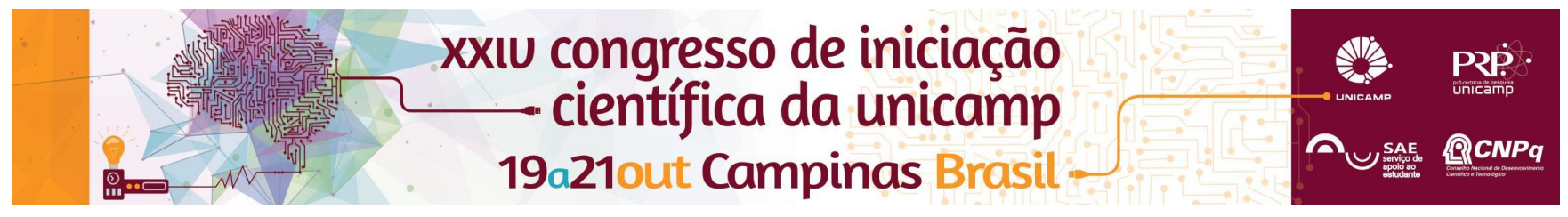

\title{
Impactos das modernas técnicas de gestão de produção na necessidade de capital de giro das empresas.
}

\author{
Pedro de Araújo S. Mansinho *, Miguel J. Bacic
}

\section{Resumo}

Neste trabalho buscou fazer uma análise afim de entender como as técnicas de gestão criadas nas indústrias orientais, lideradas pela Toyota, influenciaram na necessidade do capital de giro das empresas. Para isso foi elaborado um questionário aplicado de maneira a observar a evolução da gestão das linhas de produção nas empresas nos últimos dez anos e a consequente influencia na necessidade de capital de giro.

\section{Palavras-chave:}

Capital de Giro, Produção enxuta, Gestão .

\section{Introdução}

O presente trabalho busca fazer uma breve análise da influência das técnicas de gestão de produção, principalmente as técnicas de produção lean, no fluxo do processo produtivo e necessidade de estoque e 0 consequente impacto gerado na necessidade de capital de giro das empresas industriais. $O$ desenvolvimento do tema foi feito através de um modelo que determina os fatores que influenciam a necessidade de capital de giro das empresas e a partir disso foi feita uma breve análise das modificações que o modelo enxuto trouxe. Para tanto foram observadas alterações no fluxo produtivo, nas necessidades de estoque e no padrão de qualidade, Estes fatores são o cerne das alterações que a mentalidade enxuta trouxe e impacta a necessidade de capital de giro das empresas industriais. A partir disso foi produzido um questionário com finalidade de avaliar a relevância das técnicas de gestão de produção nas necessidades financeiras das empresas industriais.

\section{Resultados e Discussão}

O modelo dinâmico adotado relaciona a necessidade de capital de giro das empresas com os prazos de produção e os estoques, Bacic (1990). Em linhas gerais, o modelo diz que a necessidade de capital de giro (NCG), para um certo período de tempo, é determinado a partir da equação:

$N C G=\Sigma D_{C O} \cdot C O+\Sigma D_{C C} \cdot C C-\Sigma M P . P M P-$ $\Sigma D P P J \cdot P P J+E$,

onde: $\quad D c o=$ despesas correspondentes ao ciclo operacional, $C O=$ prazo do ciclo operacional, Dcc = despesas correspondentes ao ciclo comercial, $C C=$ ciclo comercial, $M P=$ gasto com matérias-primas, $P M P=$ prazo médio de compra de matérias primas, $D p p j=$ despesa $j$, PPJ = prazo de pagamento da despesa $j, E=$ Estoques (acabados e matéria-prima)

A partir da equação pode-se elaborar o questionário e analisar como os modelos de produção foram incorporados nas empresas brasileiras para que possa ser mostrado sua influência nas finanças das empresas. O questionário contou com 85 respostas válidas abrangendo empresas de diferentes setores como automobilístico, químico, têxtil, alimentício dentre outros. Os resultados obtidos em relação a linha de produção também se mostraram dentro do esperado. Nesse caso foram avaliados o comportamento do tempo médio de produção, se foi implementado algum sistema de controle de qualidade e se foi utilizada alguma ferramenta de modo a evitar o retro fluxo e paralisação. O tempo médio de produção diminuiu em $65 \%$ das empresas, $69 \%$ implementaram alguma ferramenta contra o retro fluxo, mais de $90 \%$ das empresas têm algum sistema de controle de qualidade, além da grande maioria das empresas apesar de ter seu controle de qualidade interno, possuem uma política de exigência de controle de qualidade de seus fornecedores, como normas de regulamentação ISO. Com relação aos estoques, foram avaliados três níveis médios em relação às vendas : de matéria-prima, de produtos em processo e de produtos acabados. O nível médio de estoques em relação as vendas, tanto os de produtos acabados como os de produtos em processos diminuíram, aproximadamente em $45 \%$ nas empresas nos últimos 10 anos. O nível médio de estoques de matérias primas também seguiu a mesma linha diminuindo em mais de $50 \%$ das empresas no mesmo período, mostrando que a filosofia do just-in-time que preza pelo aumento da eficiência produtiva e de estoque e surtiu efeitos positivos quanto à politica de estoques

Quanto aos prazos de compra, também foram na sua maioria estendidos, evidenciando a preocupação das empresas na diminuição da necessidade de capital de giro.

\section{Conclusões}

Com a análise dos dados obtidos através do questionário, foi possível observar a evolução nos últimos dez anos que as modernas técnicas de gestão, tais como Enxuta, Toyotismo e Just-in-Time trouxeram. Foram responsáveis por um impacto positivo na gestão financeira das empresas, uma vez que os seus principais resultados foi a diminuição dos estoques aumento da eficiência da produção, assim como uma diminuição do retrofluxo. Também observa-se aumento de prazo médio de pagamento das compras. . Assim, pelo modelo teórico adotado para a necessidade de capital de giro, evidencia-se que houve uma diminuição da NCG nas empresas que implementaram alguma das técnicas de gestão nos últimos dez anos.

\footnotetext{
BACIC, Miguel (1990) Fragilidade Financeira e Alavancagem: Uma Aplicação no Segmento das Maiores Empresas do Brasil (1980-1987).

${ }^{2}$ WOMACK, James P. e JONES, Daniel T. (1998) A Mentalidade Enxuta nas Empresas - Elimine o Desperdício e Crie Riqueza, Rio de Janeiro, Editora Campus Ltda.
} 